\title{
Morphometric analysis of the apical foramina in extracted human teeth
}

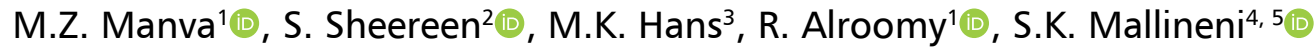 \\ ${ }^{1}$ College of Dentistry, Restorative Dental Sciences, Majmaah University, Al-Majmaah, Kingdom of Saudi Arabia \\ ${ }^{2}$ College of Dentistry, Department of Preventive Dental Sciences, Dar Al Uloom University, Riyadh, Saudi Arabia \\ ${ }^{3}$ Geetanjali Dental and Research Institute, Conservative Dentistry and Endodontics, Udaipur, Rajasthan, India \\ ${ }^{4}$ Department of Preventive Dental Science, College of Dentistry, Majmaah University, Al-Majmaah, Saudi Arabia \\ ${ }^{5}$ Centre for Transdisciplinary Research (CFTR), Saveetha Institute of Medical and Technical Sciences, Saveetha Dental \\ College, Saveetha University, Chennai, Tamil Nadu, India
}

[Received: 12 July 2020; Accepted: 14 November 2020; Early publication date: 5 December 2020]

Background: The aim of the study was to analyse the morphology of the apical foramen in permanent maxillary and mandibular human teeth.

Materials and methods: The anatomic parameters include shapes (rounded, oval, uneven, flat and semilunar) and location (centre, buccal/labial, linguall palatal, mesial, and distal) of the apical foramina was evaluated. The shapes and locations of apical foramen were analysed based on tooth type (central incisor, lateral incisor, canine, premolars, and molars) arch type (maxillary and mandibular), and position (anterior and posterior). All the teeth were investigated for the apical foramina shape and location using a stereomicroscope at a magnification of $10 \times$. Descriptive statistics performed using SPSS (Version 21.0, IBM, NY, USA) at $p$ value less than 0.05 .

Results: The common shape of apical foramina was round (65\%) and location was centre (32\%). The frequency of deviation of apical was 68\% in overall teeth. Apical foramina in maxillary anterior teeth showed more deviation while posterior teeth in mandibular teeth. The most common shape of apical foramina was round (65.1\%) followed by (31\%) and flat and semilunar shapes are very rare in studied subjects. Conclusions: The most frequent direction of deviation is the distal surface, followed by the mesial surface. The variation is more common in mandibular posterior teeth, while maxillary posteriors showed the least difference. The commonest shape of the apical foramen is of a round shape, followed by the oval. The oval shape of the apical foramen is most frequent with central incisors. (Folia Morphol 2022; 81, 1: 212-219)

Key words: apical foramina, morphology, location, shape, root, stereomicroscope

\section{INTRODUCTION}

The success of the root canal treatment includes effective mechanical preparation as well as chemical cleansing of the pulp space and its complete filling with an inert substance. Root canal morphology of teeth specifically in the apical third is a judgmentally significant factor during the endodontic treatment. It is very essential to envision and to have a thorough

Address for correspondence: Dr. M.Z. Manva, MDS, Assist. Prof., Restorative Dental Sciences, College of Dentistry, Majmaah University, Al-Majmaah, 11952, Kingdom of Saudi Arabia, tel: +966557937846, e-mail: m.manva@mu.edu.sa

This article is available in open access under Creative Common Attribution-Non-Commercial-No Derivatives 4.0 International (CC BY-NC-ND 4.0) license, allowing to download articles and share them with others as long as they credit the authors and the publisher, but without permission to change them in any way or use them commercially. 
anatomic knowledge of the tooth before root canal treatment [1]. Cautious radiographic examination and evaluation of the tooth is mandatory and Arora and Tewari [3] reported that the angled radiographs could offer the inclusive evidence of root canal morphology. Moreover, the regular radiographs may not reveal the comprehensive anatomic picture of the tooth including root as they are two-dimensional images of a three-dimensional structure [13]. The majority of the clinicians used an apical constriction as an endpoint for biomechanical preparation of the endodontic therapy. Clinically it is very difficult to establish or locate the apical constriction and apical foramen; a few prior reported studies postulated that the radiographic apex is more dependable as an endpoint [12]. The radiographic apex is the tip of the root determined by radiographs; however, the tip of the root identified morphologically is considered as anatomical apex $[3,5,7]$. Dissimilarities in the location of the radiographic apex in relation to the anatomic apex might be the result of various root morphology and radiographic distortion [14]. Prior studies have often established that the position of the apical foramen is not always located at the root apex or centre of the apex. If the apical foramen is found away from the centre it is considered as deviated and it could be distal, mesial, lingual/palatal, and labial/buccal. The occurrence of deviation of the apical foramen ranges between $46 \%$ and $92 \%[6,16]$. It has been described and it is assumed that the apical foramina is round, although studies showed that shape can vary from round to oval [18] or other shapes such as uneven, semilunar, and flat. It has been reported that it is very imperative to be aware of the occurrence of apical foramina in various ethnic groups and its anatomical variations. Numerous studies had reported diverse tendencies in the location and shapes of the apical foramina amongst the different ethnicities $[2,4,8,26]$. The prior reported studies focused on either maxillary teeth or mandibular teeth and anterior and posterior teeth. The distribution of shapes and location of apical foramina based on tooth type was not clearly discussed in the published literature. Therefore, the present study was aimed to analyse the morphology of shapes and locations of the apical foramen in permanent maxillary and mandibular human teeth based on arch, position and tooth type.

\section{MATERIALS AND METHODS}

Extracted human teeth were used in the present in-vitro study. The teeth with completely formed api- ces without any form of pathological defects were included in the study while teeth with pathological defects such as fracture, hypercementosis, root resorption (internal or external), without crowns and etc., teeth with single root of multi rooted teeth were excluded from the study. Thirty specimens of each tooth type (i.e., central incisors, lateral incisor, canine, $1^{\text {st }}$ and $2^{\text {nd }}$ premolars, $1^{\text {st }}$ and $2^{\text {nd }}$ molars) were involved in the study. All the specimens were cleaned manually from the build-up of calculus and remnants of periodontal tissues and were stored in containers filled with saline. The teeth were dried with cotton and compressed gauge, and the apical areas were stained with graphite (Apsara Platinum Extra Dark Pencils) to facilitate the identification of the apical foramen of each root. The largest diameter with opening found at the root apex was denoted as the apical foramen. Containers with number code labelled individually were used to keep the teeth separate. The specimens were mounted on a glass slide (long axis of the teeth are parallel to the glass slab) to calculate anatomic parameters. A stereomicroscope was used to examine the apical foramina at $10 \times$. The parameters of apical foramen evaluated were the shapes (rounded, oval, uneven, flat, and semilunar), location (centre, buccal, lingual, mesial, and distal) of the apical foramen of each tooth used for analysis (Figs. 1, 2). In maxillary first premolars and both maxillary and mandibular molars number of roots were considered for the analysis. It was considered as the deviation of apical foramina when a large portion of the major apical foramen $(\geq 50 \%)$ was not located at the centre. The shape and location of apical foramen in maxillary and mandibular arch were evaluated. The distribution of apical foramina-based teeth position (anterior and posterior) also evaluated .The overall distribution of apical foramina of each tooth in the entire sample was considered for final analysis. Descriptive statistics done using SPSS (version 21.0, IBM, NY, USA), and $p<0.05$ was considered statistically significant with $95 \%$ confidence interval.

\section{RESULTS}

In the present study the total number of apical foramen evaluated were 696 (maxillary: 377 and mandibular: 319 ) of 420 teeth. The commonest shape found in all evaluated apical foramen was round shape (65.1\%) followed by oval shape (31.0\%) (Fig. 3). The round shape of apical foramen was more common in mandibular teeth $(68.2 \%)$ than the maxil- 


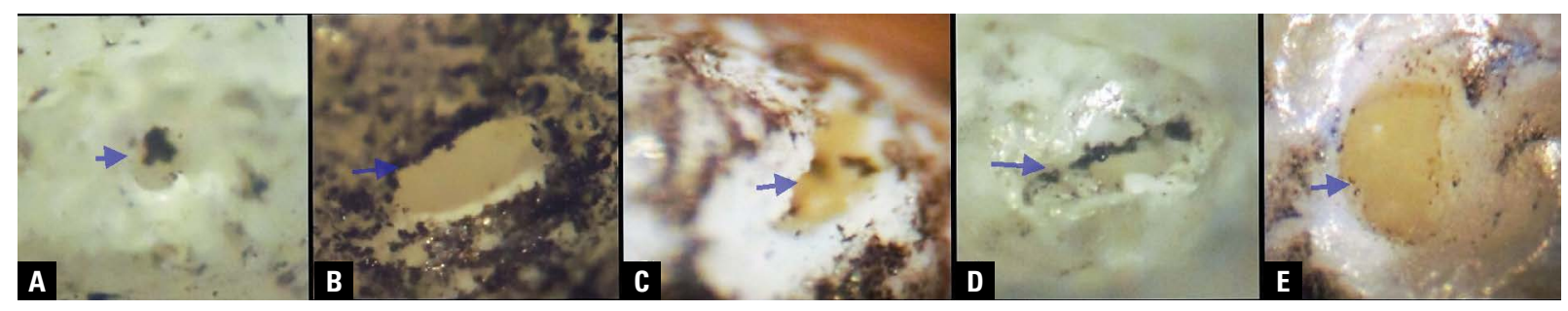

Figure 1. Shapes of apical foramina round (A), oval (B), semilunar (C), flat (D), and uneven (E) in the study.

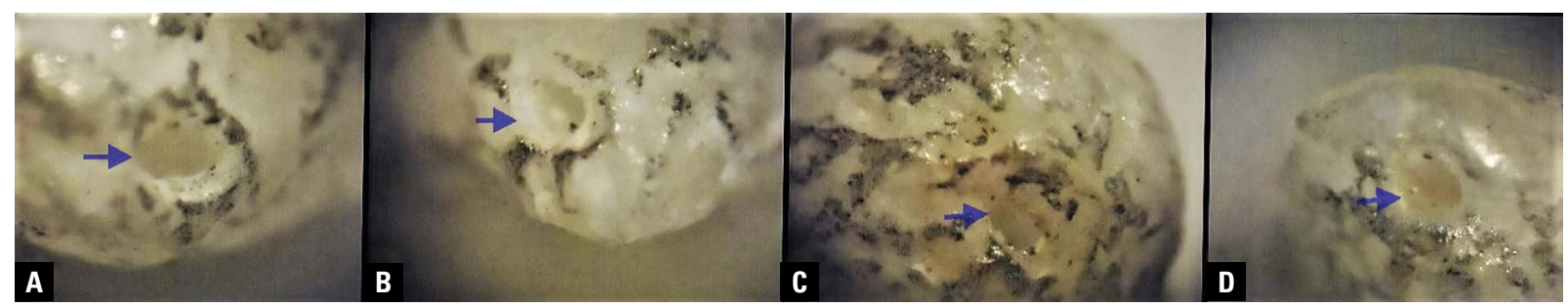

Figure 2. Deviations of the apical foramen lingually (A), buccally (B), mesially (C), and distally (D).

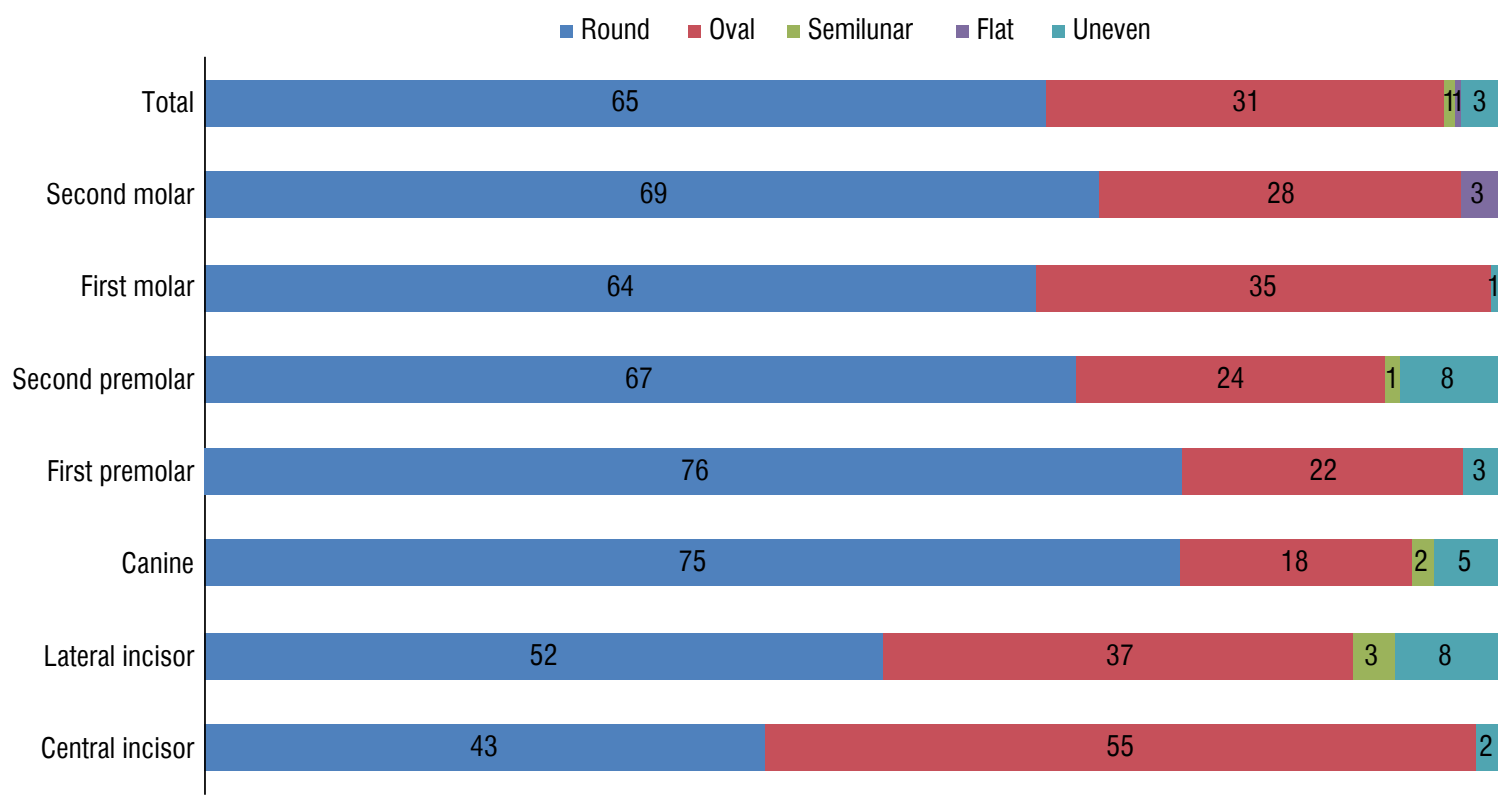

Figure 3. Distribution of shapes based on tooth type (\%).

lary teeth $(62.3 \%)$. On the other hand oval shape was more common in maxillary teeth (32.4\%) than mandibular teeth (29.6\%). The flat shape of apical foramen was only reported in maxillary teeth. The commonest shape of apical foramen for mandibular central incisors was oval with $53.3 \%$. The commonest shape was round in both anterior (57\%) and posterior teeth (68\%) (Table 1). The round shaped apical foramen was slightly more in mandibular anterior teeth (29.9\%) than the maxillary anterior teeth (27.2\%) shown in
Figure 4. Among the posterior teeth, maxillary posterior teeth reported more of round shaped apical foramen (36.1\%) than the mandibular teeth (31.6\%).

The commonest location of the apical foramen was centre $(31.6 \%)$ and the second commonest location of apical foramina distal (18.2\%) (Fig. 5). Apical foramen residing in the centre was reported more in roots of maxillary teeth (33.2\%) while it was $29.8 \%$ in roots mandibular teeth, this suggests higher deviation of apical foramen in mandibular 
Table 1. Distribution of shapes of apical foramina (\%) in anterior and posterior teeth in both the arches

\begin{tabular}{lccccc}
\hline Shapes & \multicolumn{2}{c}{ Anterior } & & \multicolumn{2}{c}{ Posterior } \\
\cline { 2 - 3 } \cline { 5 - 6 } & Maxillary & Mandibular & & Maxillary & Mandibular \\
\hline Round & 27.2 & 29.9 & & 36.1 & 31.8 \\
Oval & 18.5 & 17.9 & & 17.2 & 11.9 \\
Semilunar & 0 & 1.6 & & 0.2 & 0 \\
Flat & 0 & 0 & & 0.8 & 0 \\
Uneven & 3.3 & 1.6 & & 1.8 & 0.2 \\
Total & 49 & 51 & & 56.1 & 43.9 \\
\hline
\end{tabular}

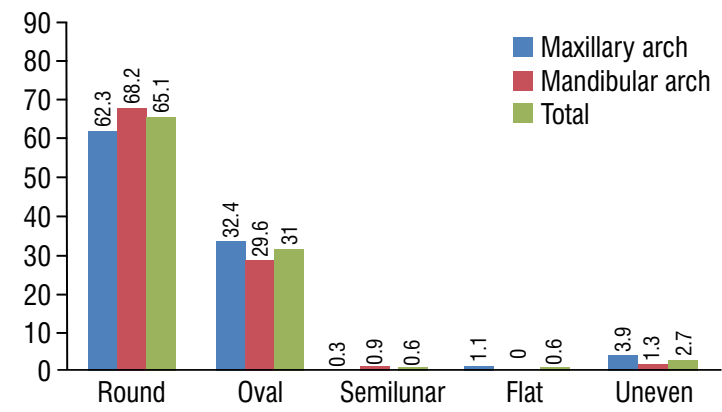

Figure 4. Distribution of shape of apical foramina in roots of maxillary and mandibular teeth.

teeth $(70.2 \%)$ the results were statistically significant $(p<0.05)$. The deviation of apical foramen was commonly reported in distal location in roots man-
Table 2. Distribution of location of apical foramina (\%) in anterior and posterior teeth in both the arches

\begin{tabular}{lccccc}
\hline \multirow{2}{*}{ Location } & \multicolumn{2}{c}{ Anterior } & & \multicolumn{2}{c}{ Posterior } \\
\cline { 2 - 3 } \cline { 5 - 6 } & Maxillary & Mandibular & & Maxillary & Mandibular \\
\hline Distal & 7.1 & 4.3 & & 9.4 & 11.3 \\
Mesial & 9.2 & 6.0 & & 9.4 & 8.8 \\
Buccal/labial & 6.0 & 16.3 & & 8.4 & 6.7 \\
Palata/lingual & 13.6 & 7.6 & & 9.2 & 4.6 \\
Centre & 13.1 & 16.8 & & 19.7 & 12.5 \\
Total & 49 & 51 & & 56.1 & 43.9 \\
\hline
\end{tabular}

Table 3. Distribution of deviation of apical foramina location (\%) in anterior and posterior teeth in both the arches

\begin{tabular}{lcclccc}
\hline \multirow{2}{*}{ Arch } & \multicolumn{2}{c}{ Anterior } & & \multicolumn{2}{c}{ Posterior } & P \\
\cline { 2 - 3 } & Centre & Deviation & & Centre & Deviation & \\
\hline Maxillary & 3.6 & 86.4 & & 19.5 & 80.5 & $<0.05$ \\
Mandibular & 16.8 & 83.2 & & 12.5 & 87.5 & \\
\hline
\end{tabular}

dibular teeth $(20.7 \%)$ while roots of maxillary teeth showed palatal deviation of apical foramen (19.1\%), which is summarised in Table 2 . Table 3 represents the percentage of commonest location of apical foramen as well the percentage of deviation among anterior and posterior teeth. In anterior teeth the deviation is more in maxillary arch with $86.4 \%$ while in posterior teeth it was more with mandibular arch with $87.5 \%$.

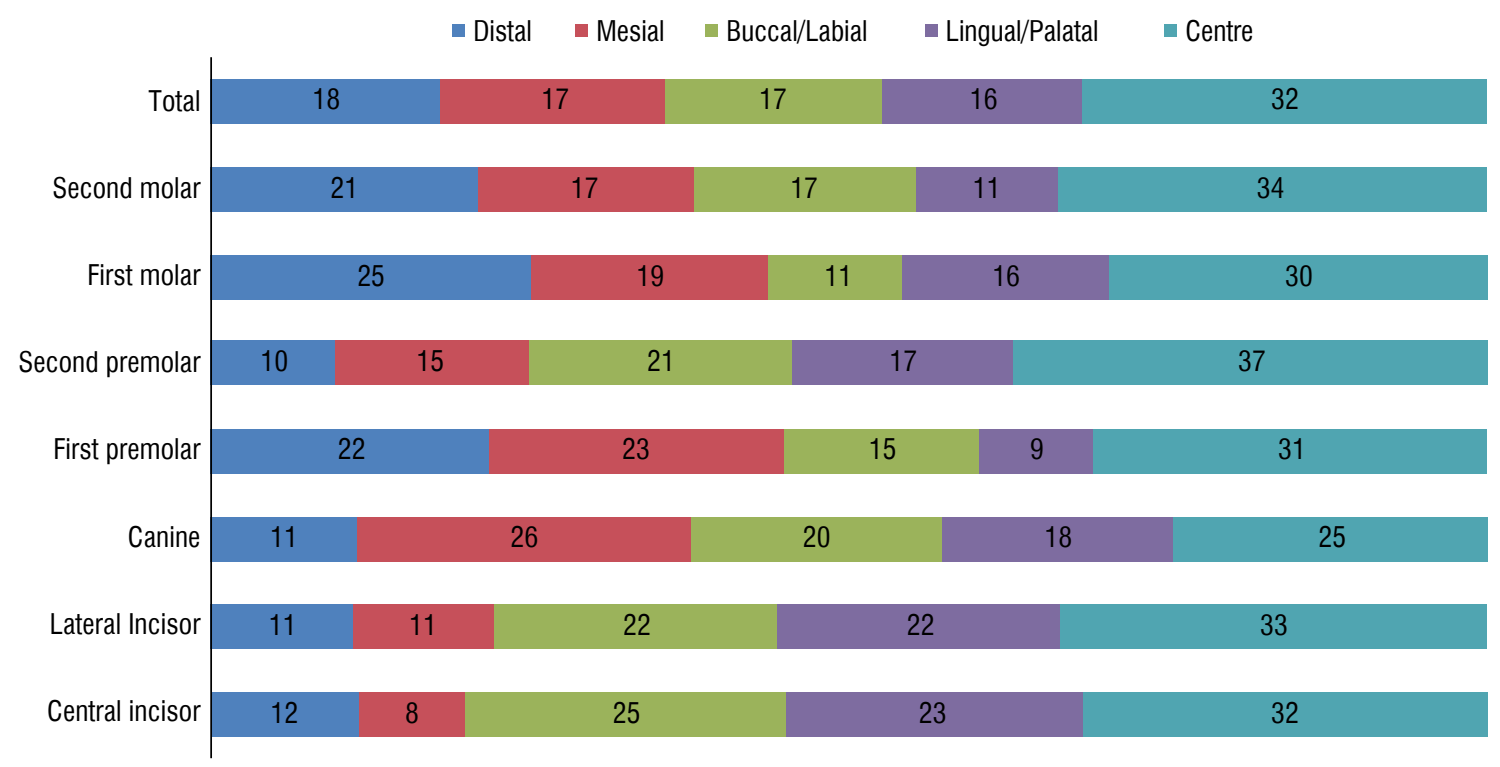

Figure 5. Distribution of location of apical foramina based tooth type (\%). 
Table 4. Distribution of shape of the apical foramina (\%) in total sample

\begin{tabular}{lcccccccc}
\hline Shapes & $\begin{array}{c}\text { Central } \\
\text { incisor }\end{array}$ & $\begin{array}{c}\text { Lateral } \\
\text { incisor }\end{array}$ & Canine & $\begin{array}{c}\text { First } \\
\text { premolar }\end{array}$ & $\begin{array}{c}\text { Second } \\
\text { premolar }\end{array}$ & $\begin{array}{c}\text { First } \\
\text { molar }\end{array}$ & $\begin{array}{c}\text { Second } \\
\text { molar }\end{array}$ & Total \\
\hline Round & 3.7 & 4.7 & 6.6 & 8.5 & 8.9 & 18.3 & 14.2 & 65.1 \\
Oval & 4.7 & 3.3 & 1.6 & 2.4 & 3.1 & 10.1 & 5.7 & 31 \\
Semilunar & 0 & 0.3 & 0.2 & 0 & 0.2 & 0 & 0 & 0.6 \\
Flat & 0 & 0 & 0 & 0 & 0 & 0 & 0.6 & 0.6 \\
Uneven & 0.2 & 0.7 & 0.4 & 0.3 & 1 & 0.2 & 0 & 2.7 \\
Total & 8.6 & 9.1 & 8.8 & 11.2 & 13.2 & 28.6 & 20.5 & $696(100)$ \\
\hline
\end{tabular}

Table 5. Distribution of location of the apical foramina (\%) in total sample

\begin{tabular}{lcccccccc}
\hline Location & $\begin{array}{c}\text { Central } \\
\text { incisor }\end{array}$ & $\begin{array}{c}\text { Lateral } \\
\text { incisor }\end{array}$ & Canine & $\begin{array}{c}\text { First } \\
\text { premolar }\end{array}$ & $\begin{array}{c}\text { Second } \\
\text { premolar }\end{array}$ & $\begin{array}{c}\text { First } \\
\text { molar }\end{array}$ & $\begin{array}{c}\text { Second } \\
\text { molar }\end{array}$ & Total \\
\hline Distal & 1 & 1 & 1 & 2.4 & 1.3 & 7.2 & 4.3 & 18.2 \\
Mesial & 0.7 & 1 & 2.3 & 2.6 & 2 & 5.3 & 3.4 & 17.4 \\
Buccal/labial & 2.2 & 2 & 1.7 & 1.7 & 2.7 & 3 & 3.6 & 17 \\
Lingual/palatal & 2 & 2 & 1.6 & 1 & 2.3 & 4.6 & 2.3 & 15.8 \\
Centre & 2.7 & 3 & 2.2 & 3.4 & 4.9 & 8.5 & 6.9 & 31.6 \\
Total & 8.6 & 9.1 & 8.8 & 11.2 & 13.2 & 28.6 & 20.5 & $696(100)$ \\
\hline
\end{tabular}

Over all common shapes was round in the roots of lateral incisors $(4.7 \%)$, canine $(6.6 \%)$, first premolar (8.5\%), second premolar (8.9\%), first molar (18.3\%) and second molar (14.2\%) while oval shape $(4.7 \%)$ was common in central incisors roots that evaluated (Table 4).The frequent location of apical foramina in roots of anterior teeth was in the maxillary arch was palatal (13.6\%) while centre location (16.8\%) of apical foramina was common in mandibular teeth followed by labial (16.3\%). The frequent location of apical foramina in the roots of posterior teeth was in the maxillary arch was centre (19.7\%) followed by mesial and digital (9.4\%), while centre (12.5\%) location followed by digital (11.3\%) in mandibular teeth (Table 5). The common location of apical foramina was centre in both maxillary and mandibular teeth (Fig. 6). The frequent deviation of apical foramina was observed in maxillary canine and very less frequently found in Maxillary second premolars (Fig. 7).

\section{DISCUSSION}

Changes in the apex's shape and location are possible under specific influences on the tooth include occlusion, adjacent drifting tooth, and pressure exerted by the tongue [24]. These subsequent changes lead to the changes in the alveolar bone around the

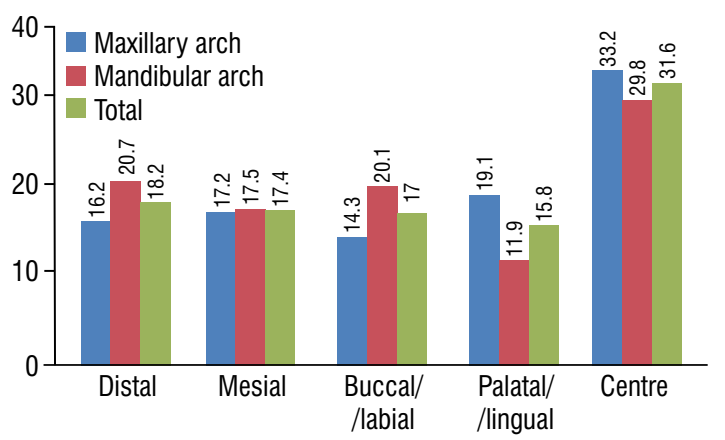

Figure 6. Distribution of location of apical foramina in roots of maxillary and mandibular teeth.

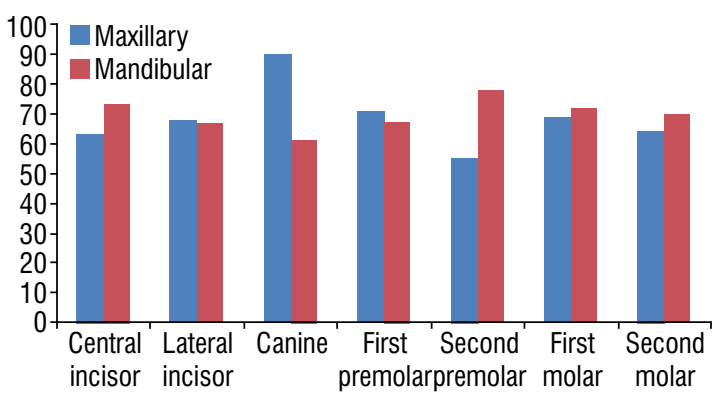

Figure 7. Distribution of deviation of apical foramina in roots based on the arch.

tooth. This might lead to resorption on the cemental wall of the apical foramen may be due to the exerted 
pressure is inevitable. Apparently, this results in the foramen's deviation that alters from the radiographic root apex [4]. Anatomy, of course, is the foundation of the art and science of healthcare. There is a need to have knowledge of the microscopic and topographic anatomy of the dental apex [12].

The anatomic parameter examined in the present study was the shape and location of the apical foramen. It was evident that the frequent location was centre and the topical shape was round. The shapes of apical foramina in the present study were classified as round $(65.1 \%)$, oval $(31 \%)$, uneven $(2.7 \%)$, semilunar $(0.6 \%)$, and flat $(0.6 \%)$. Flat shaped apical foramen was evident only in maxillary second molars teeth and not existent in any mandibular tooth type. Semilunar shaped apical foramina were evident in maxillary second premolars and mandibular lateral incisor, and canine while uneven apical foramina was not evident in second molars of both maxillary and mandibular teeth. All the tooth types found to have commonly round shaped apex more and only in central incisors where oval shaped apical foramina are frequently evident. These findings from the present study were in agreement with Chinese study [21] and Brazilian study [19]. The Chinese study examined 1282 teeth photographed by the XTL-2 photstero microscope and found $94 \%$ of an apical foramen in the study sample with a round shape [21]. On the other hand the Brazilian study found $52.9 \%$ of apical foramen was with a round shape of 1331 root specimens were evaluated. In contrast, a few prior studies $[3,10]$ found that the oval-shaped apical foramina are very common. A German study [16] reported that $71 \%$ of an apical foramen in the maxillary molars showed an oval shape, while it was evident in $53 \%$ of the roots of the mandibular molar teeth. In the present study, only $29 \%$ of 696 the apical foramen was of oval shape while $17 \%$ for maxillary posteriors and $12 \%$ for mandibular molars. An Indian study [3] reported that the commonest shape of apical foramen to be an oval shape $(81 \%)$ of 800 extracted maxillary and mandibular posterior teeth in a stereomicroscopic study. On the other hand, a Korean study [10] inspected 60 mandibular molars and found that the frequent shape of the apical foramen was an oval shape $(69.9 \%)$. However, the results from these three studies were not compared with the present study because the present study analysed all the teeth types. The Brazilian study [19] allocated their sample into incisors, canines, premolars, and molars groups, respectively, for the maxillary and mandibular arches. The authors found that the maxillary molars group showed the maximum number of apical foramina with a round shape $(67.6 \%)$. In comparison, the maxillary premolars group showed the maximum number of apical foramen with an oval shape (33.7\%). On the other hand, in the present study, we found that the mandibular canine group showed a maximum of apical foramen with a round shape ( $77.8 \%)$. In comparison, the maxillary incisors group showed a maximum of apical foramen with an oval shape (46.7\%). The German study [16] separated the specimens into four groups include mandibular first molar, mandibular second molars, maxillary first molar, and maxillary second molars. These German authors [16] found the maxillary first molar group showed more number of the oval-shaped apical foramen (74\%), while the maximum round-shaped apical foramen was found in mandibular molars (44\%).

The most common location of apical foramen was observed at the centre $(31.6 \%)$ of 696 roots (420 teeth) in the present study, followed by distal location (18.2\%). These results are in agreement with previous studies performed on the apical foramina of human teeth [18, 23]. Martos et al. [18] concluded that the commonest location of apical foramen was the centre for all evaluated groups of specimens. The results were similar to the present study except for the maxillary canine and mandibular incisors group, which showed the commonest location as lingual and buccal, respectively. A South Indian study [9] reported that $84 \%$ of evaluated roots of maxillary central incisor, $75 \%$ of the maxillary lateral incisor, and $15 \%$ of maxillary canine showed apical foramen location to be in the centre. The authors analysed only $\mathbf{2 8 5}$ roots of maxillary anterior teeth. A Brazilian study [23] investigated 84 maxillary central incisors and found that $25 \%$ of specimens with the apical foramen location in the centre. Teo et al. [25] found the apical foramens in $54.3 \%$ of the 635 maxillary central incisors Similar findings were reported by previous published studies $[27,28]$. An Iranian stereoscopic analysis of 100 maxillary central incisors found $17 \%$ of apical foramen location was in the centre [22]. A Japanese study found that $16.7 \%$ of central incisors and cuspids and $6.7 \%$ of lateral incisors have a location of an apical foramen in the centre of 90 maxillary anterior teeth [20]. In the present study, only $36.7 \%$ of maxillary central incisors, $33.3 \%$ of maxillary lateral incisors, and $10 \%$ of maxillary canines showed apical 
foramen in the centre. Another Japanese study investigated 510 maxillary central incisors and found $55 \%$ of an apical foramen in the apex [11]. In the present study, only $36.7 \%$ of maxillary central incisors, $33.3 \%$ of maxillary lateral incisors, and $10 \%$ of maxillary canines showed apical foramen in the centre. The deviation was almost $70 \%$ in anterior teeth and $67 \%$ in posterior teeth. Moreover, we have analysed the shapes and locations for the entire sample to draw the percentage of each shape and location based on tooth type. These results are first of its kind hence not compared with any of the studies published earlier. A Croatian study [17] studied the apical foramen of all anterior teeth and found that $41 \%$ of central incisors, $40 \%$ of the lateral incisors, and $38.5 \%$ of canines showed apical foramen in the centre of the apex. In the present study, $31.7 \%$ of central incisors, $33.3 \%$ of the lateral incisors, and $24.6 \%$ of canines showed apical foramen located in the centre of the apex. The Iranian study [22] found that the roots of 137 maxillary second premolars found that in the maxillary second premolar. In the present study, $29 \%$ of maxillary first premolars, $45 \%$ of maxillary second premolars, $32.5 \%$ of mandibular first premolars, and $22.8 \%$ of mandibular second premolars showed apical foramen with a central location. In the present study, $23.7 \%$ of permanent molars roots present the location of an apical foramen in the centre while it was almost similar for the distal location, with $23.4 \%$.

The clinical determination of the apical foramina is based on the clinicians' tactile sensitivity and the subjective understanding of the radiographs. The instrumentation and obturation filling should not extend beyond the apical foramen considered as effective endodontic treatment [26]. In some instances, the buccal position of apical foramina may result in over instrumentation. There is an association between the root apex and the apical foramen, which normally does not coincide [15, 25-28]. The apical foramina are very small in size, but the relatively significant anatomical variation of apical micromorphology cannot be evident in two-dimensional imaging. There is a need to use supplementary methods like an operating microscope, electronic methods and three-dimensional imaging.

\section{CONCLUSIONS}

Anatomical knowledge of apical foramina is very essential for the success of endodontic treatment. The commonest shape of the apical foramen is of a round shape, followed by the oval. The oval shape of the apical foramen is most frequent with central incisors. The common location of apical foramina was centre in all teeth and the most frequent direction of deviation is the distal surface, followed by the mesial surface. The variation is more common in mandibular posterior teeth, while maxillary posteriors showed the least difference.

\section{Ethical clearance}

The study protocol was approved by The Ethics Committee of Majmaah University Almajmaah, Saudi Arabia under the IRB No: MUREC-Nov.08/COM2020/8-1.

\section{Acknowledgements}

The authors would like to thank the Deanship of Scientific Research at Majmaah University, Al-Majmaah, Kingdom of Saudi Arabia, for supporting this work under project no. R-2022-70.

\section{Conflict of interest: None declared}

\section{REFERENCES}

1. Abarca J, Zaror C, Monardes H, et al. Morphology of the physiological apical foramen in maxillary and mandibular first molars. Int J Morphol. 2014; 32(2): 671-677, doi: 10.4067/S0717-95022014000200048, indexed in Pubmed: 25937698.

2. Al-Qudah AA, Awawdeh LA. Root canal morphology of mandibular incisors in a Jordanian population. Int Endod J. 2006; 39(11): 873-877, doi: 10.1111/j.13652591.2006.01159.x, indexed in Pubmed: 17014525.

3. Arora S, Tewari S. The morphology of the apical foramen in posterior teeth in a North Indian population. Int Endod J. 2009; 42(10): 930-939, doi: 10.1111/j.13652591.2009.01597.x.

4. Asna M, Nouri M, Mozayyeni MA, et al. Evaluation of apical foramen situation by anatomic apex and diagnostic value of radiography on determination of its location (A stereo microscopic study). J Dent Sch. 2004; 22: 361-368.

5. Basrani B, Revah S, Robinson C. Ubicacion del foramen apical. Rev Asoc Odontol Argent. 1997; 85: 230-232.

6. Cheung GSP, Yang J, Fan B. Morphometric study of the apical anatomy of C-shaped root canal systems in mandibular second molars. Int Endod J. 2007; 40(4): 239-246, doi: 10.1111/j.1365-2591.2007.01193.x, indexed in Pubmed: 17284270

7. ElAyouti A, Weiger R, Löst C. The ability of root ZX apex locator to reduce the frequency of overestimated radiographic working length. J Endod. 2002; 28(2): 116-119, doi: 10.1097/00004770-200202000-00017, indexed in Pubmed: 11833683.

8. Gulabivala K, Opasanon A, Ng YL, et al. Root and canal morphology of Thai mandibular molars. Int Endod J. 2002; 
35(1): 56-62, doi: 10.1046/j.1365-2591.2002.00452.x, indexed in Pubmed: 11853239.

9. Jain P, Balasubramanian S, Sundaramurthy J, et al. Position of apical foramina in permanent maxillary anterior teeth representative of an Indian population: An in vitro Study. J Int Oral Health. 2017; 9(6): 279, doi: 10.4103/ jioh.jioh_132_17.

10. Jeong H, Park Sj, Park SH, et al. Morphology of the apical root canal system in Korean mandibular first molar. J Korean Academy Conservative Dentistry. 2009; 34(2): 137, doi: 10.5395/jkacd.2009.34.2.137.

11. Kasahara E, Yasuda E, Yamamoto A, et al. Root canal system of the maxillary central incisor. J Endod. 1990; 16(4): 158-161, doi: 10.1016/50099-2399(06)81962-X, indexed in Pubmed: 2074404.

12. Kuttler Y. Microscopic investigation of root apexes. J Am Dent Assoc. 1955; 50(5): 544-552, doi: 10.14219/jada. archive.1955.0099, indexed in Pubmed: 14366934.

13. Mallineni SK, Anthonappa RP, King NM. Reliability of horizontal and vertical tube shift techniques in the localisation of supernumerary teeth. Eur Arch Paediatr Dent. 2016; 17(6): 455-460, doi: 10.1007/s40368-016-0253-9, indexed in Pubmed: 27848203.

14. Mallineni SK, Jayaraman J, Wong HM, et al. Dental development in children with supernumerary teeth in the anterior region of maxilla. Clin Oral Investig. 2019; 23(7): 2987-2994, doi: 10.1007/s00784-018-2709-2, indexed in Pubmed: 30374829.

15. Manva MZ, Alroomy R, Sheereen S, et al. Location and shape of the apical foramina in posterior teeth: an in-vitro analysis. Surg Radiol Anat. 2021; 43(2): 275-281, doi: 10.1007/s00276-020-02601-9, indexed in Pubmed: 33200273.

16. Marroquín BB, El-Sayed MAA, Willershausen-Zönnchen B. Morphology of the physiological foramen: I. Maxillary and mandibular molars. J Endod. 2004; 30(5): 321-328, doi: 10.1097/00004770-200405000-00005, indexed in Pubmed: 15107643.

17. Martić D, Prpić-Mehicić G, Simeon P, et al. Morphometrical analysis of main and accessory canals in apical root portion of frontal teeth. Coll Antropol. 1998; 22 Suppl: 153-159, indexed in Pubmed: 9951157.

18. Martos J, Ferrer-Luque CM, González-Rodríguez MP, et al. Topographical evaluation of the major apical foramen in permanent human teeth. Int Endod J. 2009; 42(4): 329-334, doi: 10.1111/j.1365-2591.2008.01513.x, indexed in Pubmed: 19220517.
19. Martos J, Lubian C, Silveira LF, et al. Morphologic analysis of the root apex in human teeth. J Endod. 2010; 36(4): 664-667, doi: 10.1016/j.joen.2010.01.014, indexed in Pubmed: 20307741.

20. Mizutani T, Ohno N, Nakamura H. Anatomical study of the root apex in the maxillary anterior teeth. J Endod. 1992; 18(7): 344-347, doi: 10.1016/s00992399(06)80486-3.

21. Pi X, Li C, Chen Z. [The micro-anatomy and clinical significance of the apical foramen in 1,282 permanent teeth]. Zhonghua Kou Qiang Yi Xue Za Zhi. 1996; 31 (5): 294-295, indexed in Pubmed: 9592259.

22. Rahimi S, Shahi S, Yavari HR, et al. A stereomicroscopy study of root apices of human maxillary central incisors and mandibular second premolars in an Iranian population. J Oral Sci. 2009; 51(3): 411-415, doi: 10.2334/ josnusd.51.411, indexed in Pubmed: 19776508.

23. Souza R, Figueiredo J, Colombo S, et al. Location of the apical foramen and its relationship with foraminal file size. Dental Press Endod. 2014; 1(1): 64-68, doi: 10.14436/2178-3713.1.1.064-068.oar.

24. Teng F, Du FY, Chen HZ, et al. Three-dimensional analysis of the physiologic drift of adjacent teeth following maxillary first premolar extractions. Sci Rep. 2019; 9(1): 14549, doi: 10.1038/s41598-019-51057-4, indexed in Pubmed: 31601925.

25. Teo CS, Chan NC, Loh HS. The position of the apical foramen of the permanent incisors. Aust Dent J. 1988; 33(1): 51-55, doi: 10.1111/j.1834-7819.1988.tb00628.x, indexed in Pubmed: 3044307.

26. Wasti F, Shearer AC, Wilson NH. Root canal systems of the mandibular and maxillary first permanent molar teeth of south Asian Pakistanis. Int Endod J. 2001; 34(4): 263-266, doi: 10.1046/j.1365-2591.2001.00377.x, indexed in Pubmed: 11482136.

27. Wolf TG, Anderegg AL, Yilmaz B, et al. Root canal morphology and configuration of the mandibular canine: a systematic review. Int J Environ Res Public Health. 2021; 18(19): 10197, doi: 10.3390/ijerph181910197, indexed in Pubmed: 34639498.

28. Wolf TG, Kim P, Campus G, et al. 3-Dimensional analysis and systematic review of root canal morphology and physiological foramen geometry of 109 mandibular first premolars by micro-computed tomography in a mixed swiss-german population. J Endod. 2020; 46(6): 801-809, doi: 10.1016/j.joen.2020.03.002, indexed in Pubmed: 32303349 . 